CLINICAL RESEARCH ARTICLE

\title{
Adrenal function links to early postnatal growth and blood pressure at age 6 in children born extremely preterm
}

Kristi L. Watterberg ${ }^{1}$, Susan R. Hintz ${ }^{2}$, Barbara Do ${ }^{3}$, Betty R. Vohr ${ }^{4}$, Jean Lowe ${ }^{1}$, Jamie E. Newman ${ }^{3}$, Dennis Wallace ${ }^{3}$, Conra Backstrom Lacy ${ }^{1}$, Elysia Poggi Davis ${ }^{5}$, Douglas A. Granger ${ }^{6}$, Seetha Shankaran ${ }^{7}$, Allison Payne ${ }^{8}$ and Rosemary D. Higgins ${ }^{9}$ for the SUPPORT Study Group of the Eunice Kennedy Shriver National Institute of Child Health and Human Development Neonatal Research Network

BACKGROUND: Low birth weight in term-born individuals correlates with adverse cardiometabolic outcomes; excess glucocorticoid exposure has been linked to these relationships. We hypothesized that cortisol and adrenal androgens would correlate inversely with birthweight and directly with markers of cardiometabolic risk in school-aged children born extremely preterm; further, preterm-born would have increased cortisol and adrenal androgens compared to term-born children. METHODS: Saliva samples were obtained at age 6 from 219 preterm-born children followed since birth and 40 term-born children and analyzed for dehydroepiandrosterone (DHEA) and cortisol. Cortisol was also measured at home (awakening, 30' later, evening). RESULTS: For preterm-born children, cortisol and DHEA correlated inversely with weight and length Z-scores at 36 weeks PMA and positively with systolic BP. DHEA was higher in preterm-born than term-born children (boys $p<0.01$; girls $p=0.04$ ). Cortisol was similar between preterm-born and term-born at study visit; however, preterm-born children showed a blunted morning cortisol. In term-born children, DHEA correlated with BMI $(p=0.04)$, subscapular, and abdominal skinfold thicknesses (both $p<0.01)$. CONCLUSION: Cortisol and DHEA correlated inversely with early postnatal growth and directly with systolic BP in extremely preterm-born children, suggesting perinatal programming. Blunted morning cortisol may reflect NICU stress, as seen after other adverse childhood experiences (ACEs).

Pediatric Research (2019) 86:339-347; https://doi.org/10.1038/s41390-018-0243-1

\section{INTRODUCTION}

Abundant evidence supports the developmental origins of adult disease hypothesis that intra-uterine growth restriction (IUGR) in term-born individuals can lead to a broad array of subsequent adverse outcomes, and that early glucocorticoid excess may underlie both IUGR and adverse long-term outcomes ${ }^{1-5}$. Additionally, IUGR at term gestation has been linked to subsequent increases in adrenal androgen activity and polycystic ovary syndrome ${ }^{6-8}$. The relationship of preterm birth and subsequent postnatal growth to these adverse outcomes is less clear, although data suggest that these individuals also are at higher risk for adverse outcomes linked to developmental programming, such as elevated blood pressure, insulin resistance, altered hypothalamic-pituitary-adrenal axis function, and increased adrenal androgen activity ${ }^{9-11}$.

Infants born extremely preterm have two experiences similar to those born IUGR at term gestation: growth restriction during a similar period of development (third trimester) and increased exposure to cortisol. Preterm infants are well documented to experience postnatal growth restriction. For example, a recent report from a large database of extremely preterm infants showed that the mean weight $Z$-score (weight-for-gestation) decreased from +0.05 at birth to -0.72 at discharge, and that $19.6 \%$ of the infants met their definition of growth failure at discharge, weight $<10 \%$ for age $\mathrm{e}^{12}$. In addition, both term-born IUGR newborns and extremely preterm infants experience sustained elevations of cortisol beyond that of normally developing fetuses s, $^{2,13-15}$.

We hypothesized that cortisol and adrenal androgen concentrations would be inversely proportional to birthweight in children born extremely preterm, and would correlate with evidence of adverse cardiovascular and metabolic effects. Further, based on evidence from individuals born IUGR at term gestation, we hypothesized that extremely preterm birth would be associated with increased cortisol and adrenal androgen activity at school age compared to a reference cohort of term-born children ${ }^{1-3,6,7}$.

In a large cohort of children who had been born extremely preterm (24-27 weeks GA), and in a reference cohort of children born at term gestation, we evaluated the relationship of preterm birth and perinatal factors to salivary cortisol and dehydroepiandrosterone (DHEA), a measure of adrenal androgen activity, at age 6-7. We then evaluated the relationship of cortisol and DHEA at

\footnotetext{
${ }^{1}$ University of New Mexico Health Sciences Center, Albuquerque, NM, USA; ${ }^{2}$ Department of Pediatrics, Division of Neonatal and Developmental Medicine, Stanford University School of Medicine and Lucile Packard Children's Hospital, Palo Alto, CA, USA; ${ }^{3}$ Social, Statistical and Environmental Sciences Unit, RTI International, Research Triangle Park, NC, USA; ${ }^{4}$ Department of Pediatrics, Women \& Infants Hospital, Brown University, Providence, RI, USA; ${ }^{5}$ Department of Psychology, University of Denver, Denver, CO, USA; ${ }^{6}$ Institute for Interdisciplinary Salivary Bioscience Research, University of California at Irvine, Irvine, CA, USA; ${ }^{7}$ Department of Pediatrics, Wayne State University, Detroit, MI, USA; ${ }^{8}$ Department of Pediatrics, Rainbow Babies \& Children's Hospital, Case Western Reserve University, Cleveland, OH, USA and ${ }^{9}$ Eunice Kennedy Shriver National Institute of Child Health and Human Development, National Institutes of Health, Bethesda, MD, USA

Correspondence: Kristi L. Watterberg (Kwatterberg@salud.unm.edu)

A complete list of non-author contributors appears in Appendix.
}

Received: 17 September 2018 Accepted: 9 November 2018

Published online: 12 December 2018 
age 6-7 to blood pressure and measures of adiposity. The preterm-born children had been enrolled at birth into the Surfactant Positive Airway Pressure and Pulse Oximetry (SUPPORT) randomized controlled trial conducted by the Neonatal Research Network (NRN) of the Eunice Kennedy Shriver National Institute of Child Health and Human Development $(\mathrm{NICHD})^{16}$. During the original hospitalization, a subset of infants was enrolled in the Neuroimaging and Neurodevelopmental Outcomes (NEURO) study, to examine the relationship of neonatal neuroimaging to neurodevelopmental outcomes at 18-22 months corrected age and at 6-7 years ${ }^{17}$. Partway through the 6-7 year follow-up period, the National Heart, Lung and Blood Institute (NHLBI) funded this study of adrenal function and its relationship to clinical markers of cardiovascular risk. We measured salivary cortisol and DHEA in these children and also enrolled a reference group of 40 termborn children without known medical or psychosocial diagnoses.

\section{PATIENTS AND METHODS}

\section{Population}

Fifteen NRN sites participated. All institutional review boards approved the study, and children were enrolled after parental consent. Preterm-born children were eligible if they were enrolled in the SUPPORT NEURO study (ClinicalTrials.gov ID NCT00233324); perinatal data were obtained from the original study database. The school-age visit was scheduled to occur between 6 years 4 months and 7 years 2 months old. Children who were unable to undergo neurodevelopmental testing due to severe impairment $(n=17)$ were not approached.

A reference group of 40 term-born children was recruited from 5 NRN sites. Eligible children were, by parental report: (1) singletons, 5th-95th percentile birth weight and $37-41^{6}$ weeks gestation; (2) 6 years 4 months to $<7$ years old; (3) 5th-95th percentile for height and weight; (4) never hospitalized $>2$ days; (5) without known medical problems; (6) never identified as eligible for special education, speech, or physical therapy; (7) without a sibling with autism or mental retardation; and (8) living with their birth parent(s).

\section{Procedures}

Site examiners were trained in all measurement techniques. Blood pressure (BP) and anthropometric measures were obtained at the beginning of the visit, including weight, height, head and waist circumference, and triceps, subscapular, and abdominal skinfolds. Skinfolds were measured twice on the right with a Lange Skinfold Caliper (Cambridge Scientific Industries, Inc., Cambridge, MD). If there was $>2 \mathrm{~mm}$ difference, a third measurement was made, and the two measurements within $2 \mathrm{~mm}$ of each other recorded. Weight and height were measured twice using a standard upright scale. BP was measured twice 2 min apart, using standardized equipment and techniques recommended by the Task Force on Blood Pressure for Children ${ }^{18}$.

Salivary cortisol was measured 4 times during the study visit: baseline (at beginning of visit), halfway through, after a break, and at the end. Kits were sent home to collect three additional specimens to analyze diurnal patterns: awakening, 30 min later, and evening. To maximize adherence to the protocol, parents were given an instruction brochure with pictures to illustrate the procedures and a data sheet to enter the exact times of specimen collection. Two study visit specimens were analyzed for DHEA (beginning and end), and the results were averaged. Salivary DHEA rather than its sulfate (DHEAS) was chosen as the marker of adrenal androgen activity, because the concentration of DHEAS in saliva is flow rate dependent ${ }^{19}$. Salivary hormone concentrations have been shown to correlate well with serum values ${ }^{19,20}$.

Whole, unstimulated saliva was collected by passive drool ${ }^{21}$. If the child ate or drank anything $<30 \mathrm{~min}$ before sampling, he/she rinsed out his/her mouth thoroughly before sampling; nothing was allowed by mouth $<5 \mathrm{~min}$ before sampling. Samples were frozen at $-20^{\circ} \mathrm{C}$, then shipped overnight to RTI International (Research Triangle Park, NC). All samples were sent to the Institute for Interdisciplinary Salivary Bioscience Research, where they remained at $-80^{\circ} \mathrm{C}$ until assay. Samples were thawed, centrifuged and assayed in duplicate using commercially available immunoassays designed for use with saliva without modification to the manufacturer's protocol (Salimetrics LLC, Carlsbad, CA). The test volumes were 50 and $25 \mu \mathrm{L}$. Lower limits of detection were $5 \mathrm{pg} / \mathrm{mL}$ and $0.007 \mathrm{mcg} / \mathrm{dL}$ for DHEA and cortisol, respectively. Intra- and inter-assay coefficients of variation averaged less than 10 and $15 \%$. The average of the duplicate assays was used in all statistical analyses.

\section{Statistical analysis}

Because the study sample size was limited by the original study and the timing of this study, no formal pre-study sample size calculations were conducted; however, based on the anticipated sample size of 209 , the study would have at least $80 \%$ power to detect a correlation of cortisol with weight-for-age $Z$-scores $\geq 0.19$ and $90 \%$ power to detect correlations of $\geq 0.22$. Cortisol measures included (1) value on first awakening, (2) awakening response as a change from awakening to 30 min later, (3) diurnal variation measured as the slope of the change between awakening and evening samples, and (4) stress response measured as a difference over clinic-equivalent time periods in the area under the curve (AUC) between clinic and home measures, all evaluated on a log scale. DHEA measures were treated as a two-component outcome, DHEA detected or not (adrenarche initiation) and log measured concentration for those above detection. Standard intrauterine growth charts were used for deriving birth and 36-week growth percentiles and Z-scores ${ }^{22}$. CDC growth charts were used for 18-22 months (https://www.cdc.gov/ growthcharts/cdc_charts.htm) and 6-7 years (https://www.cdc.gov/ nchs/data/series/sr_11/sr11_246.pdf).

Differences between preterm-born and term-born groups across all measures were tested by chi-square, Fisher's exact or Wilcoxon tests, as appropriate. The relationship of cortisol and DHEA to (1) perinatal factors (GA, BW-for-GA Z-score, and weight and length Z-scores at 36 weeks postmenstrual age (PMA)); (2) markers of perinatal illness (ventilation days, NEC, BPD, Grade 3 or 4 intracerebral hemorrhage $(\mathrm{ICH})$ or cystic periventricular leukomalacia (CPVL); (3) child and maternal characteristics (test age, sex, race, maternal education as a surrogate for socioeconomic status); and (4) BP and measures of adiposity (BMI, waist circumference, skin fold thickness) at 6-7 years were assessed using generalized linear models appropriate for the outcome. DHEA analyses were conducted using a two-component Bernoulli, lognormal mixture model $^{23}$. Cortisol measures were analyzed using linear models for individual time points and linear mixed models for AUC. All models controlled for study center, GA or BW Z-score, sex, and time of day, adjusting for repeated measures among each subject. $\mathrm{P}$-values did not adjust for multiple comparisons. Analyses were completed using SAS 9.4 (SAS Institute, Cary, NC).

\section{RESULTS}

NEURO school-age study visits took place between July 2012 and August 2016. Children were enrolled in the adrenal function study beginning in December of 2013; 273 preterm-born children were eligible, 247 families consented, and 219 children had at least one specimen obtained. Forty children were enrolled in the term-born AGA group and all had at least one specimen obtained the clinic visit. A total of 1433 samples were obtained; 24 were ineligible for analysis (singlet; insufficient sample), leaving 1409 samples. Of these, 423 were home specimens (112 preterm-born and 29 term-born). The only significant difference between the overall group and those who returned home samples was that the education level achieved was higher in the mothers of the preterm-born group who returned home samples $(p<0.03)$. 
Table 1. Characteristics of patients (values mean $\pm \mathrm{SD}$, median [25th-75th percentile], or $n(\%))$

\begin{tabular}{|c|c|c|c|}
\hline Neonatal characteristics & $\begin{array}{l}\text { Preterm born } \\
N=219\end{array}$ & $\begin{array}{l}\text { Term-born } \\
N=40\end{array}$ & $p$-value \\
\hline Birth weight (BW, grams) & $877 \pm 190$ & $3463 \pm 464$ & $<0.01$ \\
\hline BW < 10th \%ile $(n, \%)$ & $11(5)$ & $3(8)$ & 0.47 \\
\hline Gestational age (GA, weeks) & $26.4 \pm 1.03$ & $39.3 \pm 0.95$ & $<0.01$ \\
\hline BW for GA $Z$ score & $0.11 \pm 0.99$ & $0.13 \pm 0.89$ & 0.51 \\
\hline Male sex (\%) & $116(53)$ & $20(50)$ & 0.73 \\
\hline Race (\% white) & $137(63)$ & $33(83)$ & 0.02 \\
\hline Antenatal steroids (\%) & $207(95)$ & $0(0)$ & N/A \\
\hline Any/complete course & $178(81)$ & $0(0)$ & \\
\hline \multicolumn{4}{|l|}{ Neonatal complications } \\
\hline Necrotizing enterocolitis & $14(6)$ & $0(0)$ & \\
\hline $\begin{array}{l}\text { Bronchopulmonary } \\
\text { dysplasia }\end{array}$ & $70(32)$ & $0(0)$ & \\
\hline Days of ventilation & $7(2,27)$ & $0(0)$ & $\mathrm{N} / \mathrm{A}$ \\
\hline Severe $\mathrm{ICH}$ or $\mathrm{CPVL}^{\mathrm{a}}$ & $18(8)$ & $0(0)$ & \\
\hline Late onset sepsis & $61(28)$ & $0(0)$ & \\
\hline Severe retinopathy & $23(11)$ & $0(0)$ & \\
\hline Length at 36 weeks $(\mathrm{cm})$ & $42.8 \pm 2.8$ & & \\
\hline Length $<10$ th \%ile $(n, \%)$ & $131(73)$ & N/A & N/A \\
\hline Z-score & $-1.87 \pm 1.09$ & & \\
\hline Weight at 36 weeks & $2156 \pm 362$ & & \\
\hline Wt $<10$ th \%ile $(n, \%)$ & $115(60)$ & $\mathrm{N} / \mathrm{A}$ & $\mathrm{N} / \mathrm{A}$ \\
\hline$Z$ score & $-1.51 \pm 0.90$ & & \\
\hline $\begin{array}{l}\text { Head circumference at } \\
36 \text { weeks }\end{array}$ & $31.2 \pm 1.6$ & & \\
\hline HC < 10th \%ile $(n, \%)$ & $71(39)$ & $\mathrm{N} / \mathrm{A}$ & $\mathrm{N} / \mathrm{A}$ \\
\hline Z-score & $-1.09 \pm 1.07$ & & \\
\hline \multicolumn{4}{|l|}{ Maternal characteristics } \\
\hline \multicolumn{4}{|l|}{ Maternal education } \\
\hline $\begin{array}{l}\text { Did not complete high } \\
\text { school }\end{array}$ & $53(25)$ & $0(0)$ & $<0.01$ \\
\hline $\begin{array}{l}\text { Completed high } \\
\text { school }\end{array}$ & $66(31)$ & $2(5)$ & \\
\hline Some post-secondary & $51(24)$ & $1(3)$ & \\
\hline Completed college & $32(15)$ & $19(49)$ & \\
\hline $\begin{array}{l}\text { Any graduate } \\
\text { education }\end{array}$ & $11(5)$ & $17(44)$ & \\
\hline Diabetes & $13(6)$ & $\mathrm{N} / \mathrm{A}$ & $\mathrm{N} / \mathrm{A}$ \\
\hline Hypertension & $53(24)$ & $3(8)$ & 0.03 \\
\hline \multicolumn{4}{|l|}{ Characteristics at follow-up } \\
\hline Child test age (years) & $6.9 \pm 0.43$ & $6.7 \pm 0.20$ & 0.51 \\
\hline Height $(\mathrm{cm})$ & $119.7 \pm 6.9$ & $121.7 \pm 5.3$ & 0.04 \\
\hline$Z$ score & $-0.17 \pm 1.23$ & $0.40 \pm 0.93$ & $<0.01$ \\
\hline Weight (kg) & $22.8 \pm 4.7$ & $23.0 \pm 3.5$ & 0.53 \\
\hline Z score & $-0.17 \pm 1.18$ & $0.12 \pm 0.88$ & 0.08 \\
\hline BMI & $16.0 \pm 2.5$ & $15.5 \pm 1.5$ & 0.30 \\
\hline Waist/height ratio & $0.48 \pm 0.06$ & $0.46 \pm 0.03$ & 0.06 \\
\hline \multicolumn{4}{|l|}{ Skinfolds (mm) } \\
\hline Triceps & $9.64 \pm 4.37$ & $8.66 \pm 2.52$ & 0.83 \\
\hline Abdominal & $8.96 \pm 6.11$ & $7.28 \pm 3.94$ & 0.21 \\
\hline Subscapular & $6.64 \pm 3.92$ & $5.90 \pm 2.36$ & 0.49 \\
\hline \multicolumn{4}{|l|}{ Blood pressure $(\mathrm{mm} \mathrm{Hg})$} \\
\hline Systolic & $101.5 \pm 8.9$ & $97.3 \pm 10.3$ & 0.19 \\
\hline
\end{tabular}

\begin{tabular}{|clll|}
\hline Table 1 continued & & & \\
\hline Neonatal characteristics & $\begin{array}{l}\text { Preterm born } \\
N=219\end{array}$ & $\begin{array}{l}\text { Term-born } \\
N=40\end{array}$ & $p$-value \\
\hline Diastolic & $63.3 \pm 8.1$ & $62.6 \pm 7.5$ & 0.99 \\
$\begin{array}{l}\text { Salivary DHEA pg/ml } \\
\text { (median, 25-75\%) }\end{array}$ & & & \\
All children & $17.6[3.1-43.4]$ & $10.3[0.0-22.9]$ & 0.01 \\
Boys & $17.0[0.0-40.4]$ & $7.0[0.0-13.5]$ & $<0.01$ \\
Girls & $17.7[0.0-47.7]$ & $16.8[5.0-45.7]$ & 0.75 \\
Number of samples & $290(71)$ & $51(65)$ & 0.31 \\
positive $(n, \%)$ & $152(70)$ & $22(55)$ & 0.06 \\
Boys & $138(72)$ & $29(76)$ & 0.61 \\
$\quad$ Girls & 29.2 & 18.2 & $<0.01$ \\
Salivary DHEA $\geq 5 \mathrm{pg} / \mathrm{mL}$, & {$[14.8-54.4]$} & {$[11.2-31.3]$} & \\
all children & 28.2 & $12.6[9.0-20.6]$ & $<0.01$ \\
Boys & {$[14.3-47.7]$} & & \\
Girls & 32.4 & 23.1 & 0.04 \\
& {$[15.1-60.1]$} & {$[13.4-50.3]$} &
\end{tabular}

a Severe ICH intracranial hemorrhage grade III or IV; $C P V L$ cystic periventricular leukomalacia

Table 1 shows maternal and infant characteristics. More termborn children were white, and their mothers had attained a higher educational level. These factors were included in all analyses. In the preterm-born group, the mean weight Z-score (weight-forgestation) decreased from +0.11 to -1.51 by 36 weeks PMA, and $60 \%$ had a 36 -week $Z$-score $<10$ th percentile ${ }^{22}$. At age 6 , the preterm-born children were shorter than the term-born children ( $p=0.04$ for height; $p<0.01$ for height $Z$-score).

Table 2 shows the relationship of maternal and child factors to cortisol AUC. The AUC for cortisol in clinic was higher than the area under the equivalent time period of the home curve $(p<$ 0.001); however, there was no increase seen in response to the study visit. Cortisol AUC did not correlate with BW Z-score; however, it correlated inversely with 36 -week weight and length $Z$-scores (Table 2; weight $p=0.01$ (shown in Fig. 1a), length $p=$ $0.03)$. These $Z$-scores did not correlate significantly with individual cortisol values. Preterm-born children had a blunted morning cortisol compared to term-born children (Fig. 2, $p=0.02$ ). Although evening values were lower in the preterm-born children, the difference was not significant. As $95 \%$ of the preterm-born children were exposed to antenatal glucocorticoids, we could not analyze the effect of that exposure on this finding.

Table 3 shows factors associated with measurable salivary DHEA and DHEA concentration. As anticipated, DHEA was not measurable at this age in all children ${ }^{24}$. In children with measurable DHEA (71\% preterm-born, $65 \%$ term-born), values were higher in preterm-born (boys $p<0.01$, girls $p=0.04$ ). Although values appeared lower in boys, the sex difference was not significant. For preterm-born, lower DHEA values were seen in white children $(p<0.01)$, consistent with other reports ${ }^{25}$. BW Zscore was not related to DHEA; however, weight $Z$-score at 36 weeks PMA was inversely related both to having measurable DHEA and to DHEA concentration (Table 3 and Fig. 1b). Length Zscore was inversely related to DHEA concentration $(p<0.01)$. Weight gain velocity between birth and 36 weeks PMA also inversely correlated with DHEA concentrations $(p=0.03)$. Weight gain velocity after 36 weeks PMA was not associated with cortisol or DHEA values.

Both cortisol and DHEA correlated significantly with systolic BP in the preterm-born children (Fig. 1c, d), but not the term-born reference cohort. In term-born children, measurable DHEA was 
Table 2. Associations between patient characteristics (adjusted for center, time of clinic visit, sex and birthweight $Z$-scores) and area under the curve (AUC) for all cortisol values

\begin{tabular}{|c|c|c|c|c|}
\hline Characteristic & \multicolumn{2}{|l|}{ Preterm born } & \multicolumn{2}{|l|}{ Term born } \\
\hline Gestational age & $0.98(0.92,1.05)$ & 0.59 & $0.92(0.71,1.20)$ & 0.53 \\
\hline Male & $1.04(0.91,1.19)$ & 0.57 & $1.01(0.65,1.57)$ & 0.96 \\
\hline White & $0.87(0.75,1.01)$ & 0.07 & $0.87(0.49,1.54)$ & 0.62 \\
\hline Maternal education & $1.13(0.98,1.30)$ & 0.09 & $1.40(0.84,2.35)$ & 0.19 \\
\hline \multicolumn{5}{|l|}{ Perinatal factors } \\
\hline BPD & $1.02(0.88,1.19)$ & 0.76 & - & - \\
\hline ROP & $0.96(0.76,1.22)$ & 0.76 & - & - \\
\hline NEC & $1.03(0.78,1.37)$ & 0.83 & - & - \\
\hline Severe $\mathrm{ICH} / \mathrm{CPVL}$ & $1.00(0.77,1.30)$ & 0.98 & - & - \\
\hline 36-week HC Z-score & $1.00(0.92,1.08)$ & 0.96 & - & - \\
\hline \multicolumn{5}{|l|}{ Weight gain velocity } \\
\hline Birth to $36 \mathrm{wks}$ & $0.06(0.00,0.98)$ & 0.05 & - & - \\
\hline $36 \mathrm{wks}$ to $18-22 \mathrm{mos}$ & $1.33(0.46,3.79)$ & 0.59 & - & - \\
\hline 2 yrs to study visit & $0.95(0.30,3.03)$ & 0.93 & - & - \\
\hline \multicolumn{5}{|l|}{ Adiposity measures } \\
\hline $\mathrm{BMI}$ & $1.01(0.98,1.04)$ & 0.66 & $0.98(0.81,1.19)$ & 0.86 \\
\hline Waist:height ratio & $1.16(0.32,4.23)$ & 0.83 & $0.01(0.00,167.58)$ & 0.34 \\
\hline \multicolumn{5}{|l|}{ Skinfold thickness } \\
\hline Triceps & $1.01(0.86,1.19)$ & 0.88 & $1.87(0.71,4.90)$ & 0.19 \\
\hline Subscapular & $1.02(0.86,1.22)$ & 0.81 & $2.38(0.88,6.45)$ & 0.08 \\
\hline
\end{tabular}

associated with higher BMI $(p=0.04)$, and increased subscapular $(p<0.01)$ and abdominal $(p<0.01)$ skinfold thickness measures.

\section{DISCUSSION}

Based on previously published data from individuals born preterm or IUGR at term gestation, we had hypothesized that extremely preterm birth would result in increased cortisol and adrenal androgen concentrations at age 6 compared to term-born children $1-3,6,7,11,26,27$. Our results were both more complex and physiologically compelling. Instead of higher cortisol values, preterm-born children demonstrated a blunted morning cortisol compared to term-born children.

Although this was an unexpected finding, it is consistent with more recently published work regarding the long-term impact of early life pain, institutionalization, adverse childhood experiences (ACEs), trauma, and sustained stress on dysregulation of the HPA axis, with physiologic and psychological consequences ${ }^{28-34}$. One group of investigators recently reported that school-age children born very preterm had significantly lower levels of cortisol at awakening than term-born children ${ }^{29}$, while another has shown that greater exposure to painful procedures in the NICU correlated with lower morning cortisol values at age 7 in preterm-born children $^{30,31}$. Additionally, adults born extremely preterm have been shown to have a lower response to a social stress test ${ }^{10}$. These findings may parallel outcomes after other experiences of significant stress. For example, children who experienced early rearing in an orphanage showed a blunted cortisol awakening response when tested between ages $7-15^{33}$. Additionally, the number of adverse childhood experiences (ACEs) has been reported to correlate inversely with hair cortisol in adults ${ }^{32}$. Similar findings have been reported in individuals after trauma and in those with post-traumatic stress disorder ${ }^{34}$. The pretermborn children in our study were all $<28$ weeks gestation at birth and experienced long NICU stays likely to entail numerous painful and unpleasant procedures and sustained stress.

We did find, as we had postulated, that children born extremely preterm had higher salivary DHEA concentrations at age 6 than the term-born children. Low birth weight in term-born individuals has been associated with higher adrenal androgens later in life, as well as increased risk for hypertension and other features of the metabolic syndrome, in particular polycystic ovary syndrome $1,2,6,11,24,27$. The extra-uterine growth restriction experienced by these extremely preterm infants may have resulted in higher subsequent adrenal androgen concentrations, similar to intrauterine growth restriction in infants born at term. Our findings are 

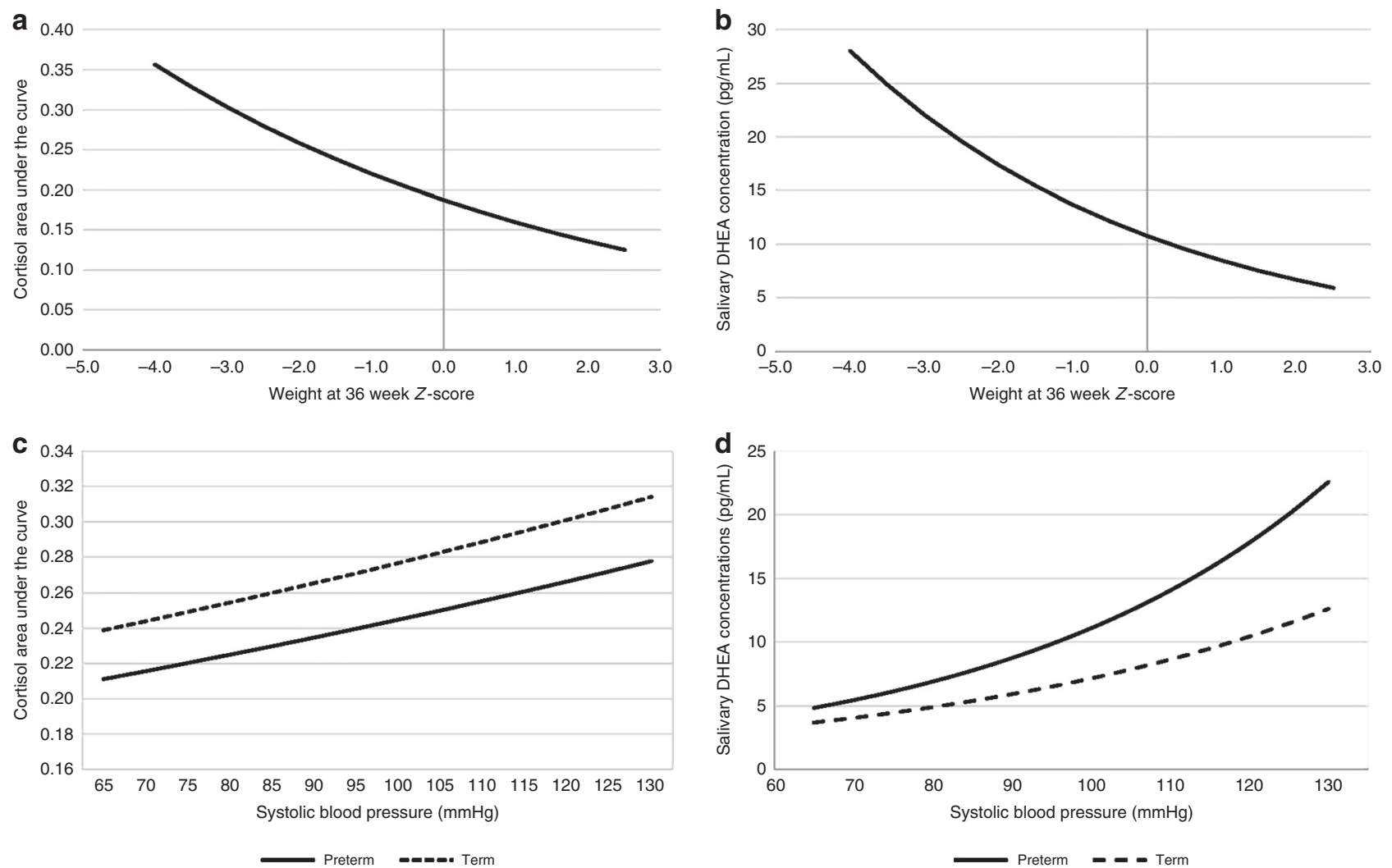

Fig. 1 The relationship of cortisol and DHEA to Z-scores for weight at 36 weeks postmenstrual age in children born extremely preterm (Panels $\mathbf{a}$ and $\mathbf{b}$, significant for both cortisol $(0.85(0.75,0.96), p=0.01)$ and DHEA $(0.78(0.63,0.95), p=0.02)$ and to systolic blood pressure in children born extremely preterm (plain line) and in those born at term (dashed line) (panels c and d), significant for preterm-born (cortisol 1.09 (1.00, 1.18), $p=0.04$; DHEA 1.24 (1.01, 1.51), $p=0.04$ ), but not term-born children (cortisol $1.11(0.86,1.43), p=0.39 ;$ DHEA 1.12 (0.81, 1.55) $p=0.48)$, possibly due to a smaller sample size

consistent with Meuwese and colleagues, who reported that young adults born very preterm showed elevated DHEAS and androstenedione, particularly when born small for gestational age $(\mathrm{SGA})^{11}$. We speculate that inconsistent data regarding the effect of preterm birth and birth weight on subsequent adrenal androgen secretion may be due to differences in gestational age, degree of illness, and/or growth between birth and 36 weeks $\mathrm{PMA}^{24,26,35}$.

We next hypothesized that birth weight would correlate inversely with cortisol and DHEA concentrations, as previously shown in IUGR term-born individuals $\mathrm{s}^{6,8,27}$. However, rather than birth weight, we found a significant inverse relationship between weight and length Z-scores at 36 weeks and both cortisol and DHEA concentrations. This relationship mirrors that of the IUGR infant at term, and may have the same etiology: growth restriction and increased exposure to cortisol during a similar period of development. Children born extremely preterm experienced progressive growth restriction through 36 weeks PMA: mean weight $Z$-score dropped from +0.11 at birth to -1.51 by 36 weeks PMA, and $60 \%$ of the infants had a weight below the 10th percentile ${ }^{22}$.

During pregnancy, SGA fetuses have been reported to have higher cortisol values than AGA fetuses ${ }^{4}$. In addition, placentas from pregnancies with growth-restricted fetuses show decreased 11-beta hydroxysteroid dehydrogenase Type 2 (11bHSD2), which normally inactivates maternal cortisol, thereby shielding the fetus from excess cortisol exposure ${ }^{5}$. A reduction in 11 bHSD2 activity results in more maternal cortisol reaching the fetus ${ }^{3,5}$. While we do not have cortisol values for these children during their initial hospitalization, previous studies have consistently found cortisol values in sick extremely preterm infants to be higher than normal fetuses of the same gestation. Median fetal values at 26 weeks gestation have been reported to be about $3 \mathrm{mcg} / \mathrm{dL}^{4,13}$, while median concentrations more than 3 -fold higher have been reported in extremely preterm infants during the first postnatal weeks $^{14,15,36,37}$.

Finally, we confirmed our hypothesis that cortisol and DHEA concentrations would correlate with markers of cardiometabolic risk at age 6. For children born extremely preterm, increasing concentrations correlated with increasing systolic BP values (Fig. 1, panels $\mathrm{c}$ and $\mathrm{d}$ ). This correlation is noteworthy because blood pressure in childhood correlates with subsequent adult values ${ }^{38}$. In the term-born children, the relationships visually appeared similar, but the correlations were not significant, perhaps due to the smaller sample size. In term-born children, higher DHEA correlated with measures of adiposity (BMI and skinfold thicknesses), consistent with previous reports ${ }^{8,39}$, also a risk factor for adverse cardiometabolic outcomes ${ }^{2,24}$.

We did not find an effect of weight gain velocity after 36 weeks, in contrast to some previous studies ${ }^{8,35}$. Our findings may differ for any of a number of reasons; for example, our cohort was born at a lower gestational age (mean 26 weeks), included very few infants born SGA, and experienced many morbidities of prematurity ${ }^{16}$. We did not find an association with any specific perinatal morbidity; however, early growth failure may be a proxy for overall severity of illness. White race was associated with lower DHEA concentrations, as others have reported; ${ }^{25}$ this factor was included in all analyses. Older age at testing was associated with increased DHEA in the preterm-born cohort, but not in the term-born children, possibly due to a 
a

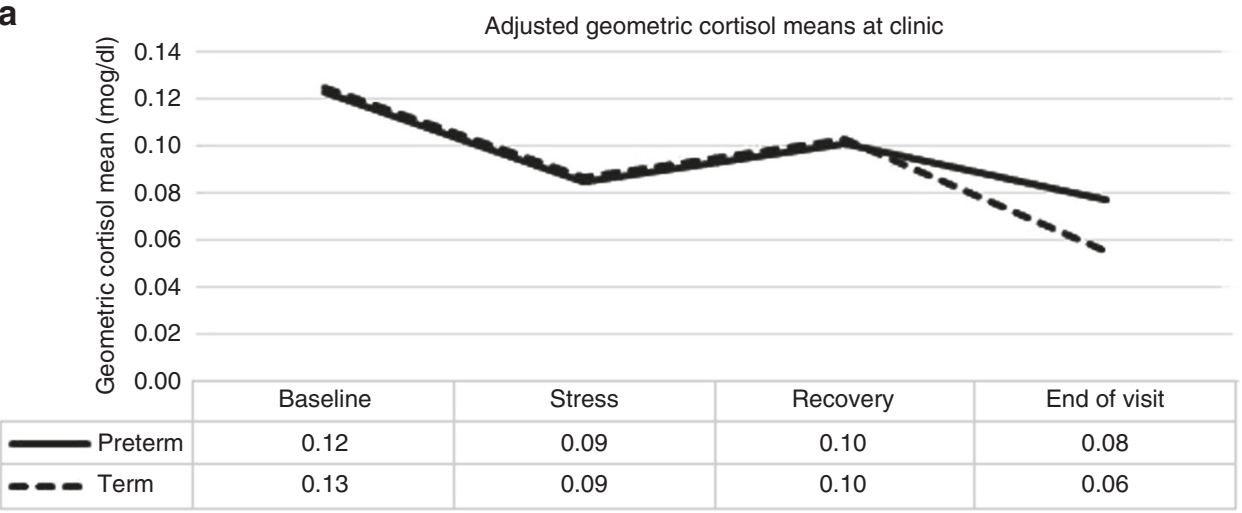

Time points at clinic visit

b

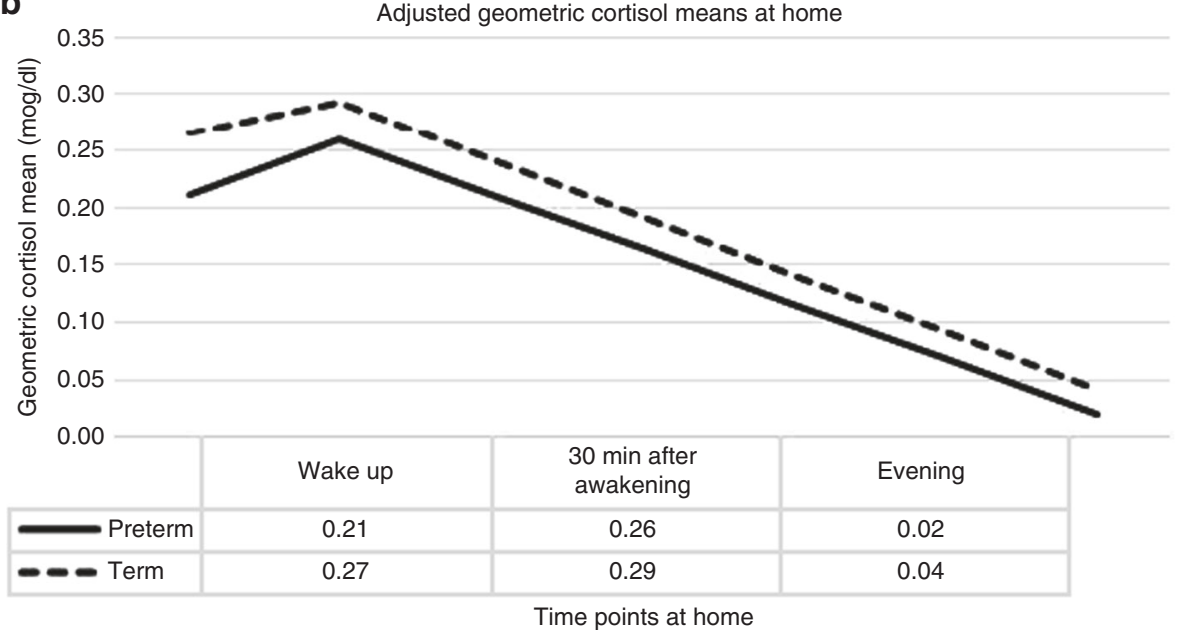

Fig. 2 Cortisol concentrations during clinic visit (a) and at home (b) for extremely preterm born (plain line) and term-born children (dashed line). Preterm-born children had blunted morning cortisol values $(1.09(1.00,1.18), p=0.02)$, with geometric mean values $22 \%$ lower on awakening and $10 \%$ lower at 30 min than term-born children

narrower testing window for the term-born children (SD of 0.20 years for term vs. 0.43 years for preterm). Adrenal androgen values increase gradually over time at this age, prior to the appearance of clinical signs of adrenarche ${ }^{24}$.

Limitations of our study included the low number of extremely preterm-born children who were SGA $(11 ; 5 \%)$, limiting our ability to assess the effect of birth weight $<10$ th percentile on outcomes, and the low rate of return of home samples. Characteristics of the families that returned home samples were similar to those who did not, with the exception of a higher maternal educational level in families who returned samples. In addition, our term-born group was recruited for this study; therefore, detailed perinatal data were not available. We made every effort to recruit children without a history of medical or psychosocial diagnoses, to create a healthy reference cohort; however, because these children were quite healthy, differences between the two groups may have been accentuated. Strengths of the study include our large cohort of extremely preterm-born children with detailed perinatal and 18-22-month data, and our research infrastructure, which provided specific training in obtaining anthropomorphic measurements and saliva specimens.

Our findings highlight the potential importance of growth restriction after extremely preterm birth as a contributing factor to adverse outcomes. Although growth to hospital discharge has improved for extremely preterm infants, maintaining adequate growth in sick preterm infants remains a challenge, resulting in significant growth restriction in the most immature patients, such as those in this study ${ }^{12,40}$. One often overlooked aspect of supporting postnatal growth and development in these infants is decreasing exposure to endogenous cortisol. One group of investigators has linked the total number of painful procedures experienced in the NICU, a proxy for the stress experienced, to alterations in the HPA axis in childhood, including lower diurnal cortisol values at age $7^{30,31}$. Interventions to decrease cortisol production in the preterm infant can include not only decreasing noxious experiences and environmental stressors ${ }^{28,41}$, but also increasing positive exposures, such as skin-to-skin care and other soothing interventions ${ }^{41}$. Achieving the goal of sustaining appropriate postnatal growth in extremely preterm infants may have life-long ramifications.

In conclusion, we found that early postnatal growth restriction in infants born extremely preterm was associated with increased cortisol and DHEA at age 6-7 years. In turn, higher salivary cortisol and DHEA concentrations correlated with higher systolic BP in these children, suggesting future cardiovascular risk. We also found that infants born extremely preterm had blunted morning cortisol compared to a term-born reference group, similar to findings in other individuals who have experienced significant stress. Reducing stress in the neonatal intensive care unit could alter these outcomes, and studies are urgently needed. 


\begin{tabular}{|c|c|c|c|c|c|c|c|c|}
\hline Characteristic & \multicolumn{4}{|l|}{ Preterm-born } & \multicolumn{4}{|l|}{ Term-born } \\
\hline Gestational age & $1.20(0.33,4.32)$ & 0.78 & $1.08(0.91,1.28)$ & 0.39 & $2.78(0.13,60.06)$ & 0.51 & $0.79(0.49,1.27)$ & 0.34 \\
\hline White & $1.11(0.32,3.89)$ & 0.87 & $0.55(0.38,0.78)$ & $<0.01$ & $0.45(0.02,11.04)$ & 0.62 & $0.61(0.25,1.50)$ & 0.29 \\
\hline Maternal education & $0.52(0.20,1.31)$ & 0.16 & $1.09(0.90,1.31)$ & 0.38 & $0.18(0.02,1.91)$ & 0.15 & $0.56(0.31,1.02)$ & 0.07 \\
\hline $\begin{array}{l}\text { Maternal } \\
\text { hypertension }\end{array}$ & $4.67(0.67,32.32)$ & 0.12 & $1.21(0.82,1.78)$ & 0.35 & $2.57(0.03,232.48)$ & 0.67 & $0.96(0.25,3.72)$ & 0.96 \\
\hline Maternal diabetes & $13.88(0.00,1265.29)$ & 0.78 & $1.26(0.60,2.67)$ & 0.54 & - & - & - & - \\
\hline Severe $\mathrm{ICH} / \mathrm{cPVL}$ & $0.27(0.06,1.26)$ & 0.10 & $1.58(0.72,3.48)$ & 0.25 & - & - & - & - \\
\hline $\begin{array}{l}\text { Birth weight } Z \text { - } \\
\text { score }\end{array}$ & $0.53(0.27,1.04)$ & 0.07 & $0.89(0.72,1.11)$ & 0.31 & $0.36(0.11,1.25)$ & 0.10 & $1.11(0.76,1.63)$ & 0.60 \\
\hline $\begin{array}{l}\text { 36-week weight } \\
Z \text {-score }\end{array}$ & $0.33(0.13,0.86)$ & 0.02 & $0.78(0.63,0.95)$ & 0.02 & - & - & - & - \\
\hline $\begin{array}{l}\text { 36-week Length } \\
Z \text {-score }\end{array}$ & $0.80(0.43,1.49)$ & 0.48 & $0.77(0.65,0.92)$ & $<0.01$ & - & - & - & - \\
\hline $\begin{array}{l}\text { 36-week HC Z- } \\
\text { score }\end{array}$ & $0.75(0.35,1.63)$ & 0.47 & $0.80(0.66,0.98)$ & 0.03 & - & - & - & - \\
\hline \multicolumn{9}{|l|}{ Weight gain velocity } \\
\hline Birth to 36 wks & $0.26(0.03,2.16)$ & 0.21 & $0.52(0.29,0.93)$ & 0.03 & - & - & - & - \\
\hline \multicolumn{9}{|l|}{$\begin{array}{l}\text { Skinfold } \\
\text { thickness }\end{array}$} \\
\hline Triceps & $1.11(0.92,1.35)$ & 0.28 & $1.01(0.97,1.05)$ & 0.54 & $1.11(0.76,1.61)$ & 0.59 & $1.12(0.99,1.27)$ & 0.09 \\
\hline Subscapular & $1.24(0.91,1.69)$ & 0.17 & $1.03(0.99,1.08)$ & 0.16 & $0.86(0.52,1.40)$ & 0.53 & $1.27(1.13,1.44)$ & $<0.01$ \\
\hline Abdominal & $1.19(0.93,1.51)$ & 0.17 & $1.02(0.99,1.05)$ & 0.25 & $0.78(0.58,1.06)$ & 0.11 & $1.19(1.09,1.30)$ & $<0.01$ \\
\hline \multicolumn{9}{|l|}{ Blood pressure ${ }^{c}$} \\
\hline Systolic & $1.19(0.54,2.62)$ & 0.66 & $1.24(1.01,1.51)$ & 0.04 & $0.48(0.14,1.62)$ & 0.23 & $1.12(0.81,1.55)$ & 0.48 \\
\hline Diastolic & $0.93(0.44,1.97)$ & 0.86 & $1.20(0.97,1.48)$ & 0.09 & $1.15(0.27,4.97)$ & 0.85 & $0.97(0.63,1.49)$ & 0.89 \\
\hline Age at testing & $2.19(0.32,14.93)$ & 0.42 & $1.66(1.11,2.49)$ & 0.02 & $1.38(0.00,4124.11)$ & 0.94 & $1.69(0.24,11.85)$ & 0.60 \\
\hline $\begin{array}{l}{ }^{\mathrm{a}} \text { Odds ratio tested the } \\
\text { of } 5 \mathrm{pg} / \mathrm{mL} \\
{ }^{\mathrm{b}} \mathrm{Given} \text { a subject had } \\
\text { relative (i.e., multiplic } \\
\text { row of the term-born } \\
{ }^{\mathrm{c}} \text { Unit }=\text { every } 10 \mathrm{mml}\end{array}$ & $\begin{array}{l}\text { binomial probability of e } \\
\text { measurable concentratio } \\
\text { ative) impact of a one-uni } \\
\text { column indicates that for } \\
\mathrm{Hg}\end{array}$ & J & $\begin{array}{l}\text { e the detection I } \\
\text { geometric mean } \\
\text { ease in gestation }\end{array}$ & A con & $\begin{array}{l}\mathrm{nL} \text {, left-censored } \\
\text { tration. For exan } \\
\text { metric mean DH }\end{array}$ & 况 & $\begin{array}{l}\text { HEA above the dete } \\
\text { ed models then pre } \\
\text { or term born infants } \\
\text { on decreases by a fac }\end{array}$ & $\begin{array}{l}\text { on limit } \\
\text { ted the } \\
\text { he first } \\
\text { of } 0.79\end{array}$ \\
\hline
\end{tabular}

\section{ACKNOWLEDGMENTS}

The National Institutes of Health, the Eunice Kennedy Shriver National Institute of Child Health and Human Development (NICHD), and the National Heart, Lung, and Blood Institute (NHLBI) provided grant support for the Neonatal Research Network's Extended Follow-up at School Age for the SUPPORT Neuroimaging and Neurodevelopmental Outcomes (NEURO) Cohort through cooperative agreements. NHLBI provided support for this study (R01HL117764). While NICHD staff had input into the study design, conduct, analysis, and manuscript drafting, the comments and views of the authors do not necessarily represent the views of the NICHD. Data collected at participating sites of the NICHD Neonatal Research Network (NRN) were transmitted to RTI International, the data coordinating center (DCC) for the network, which stored, managed and analyzed the data for this study. On behalf of the NRN, Drs. Abhik Das (DCC Principal Investigator), Marie Gantz, Lisa Wrage, and Helen Cheng (DCC Statisticians) had full access to all the data in the study and take responsibility for the 
integrity of the data and accuracy of the data analysis. We are indebted to our medical and nursing colleagues and the infants and their parents who agreed to take part in this study.

\section{AUTHOR CONTRIBUTIONS}

K.W. made substantial contributions to conception and design of the study, acquisition, analysis, and interpretation of data. She drafted the initial manuscript, revised it, and has given final approval of the version to be published. S.H. provided resources for the study, made substantial contributions to the investigation, reviewed and edited the manuscript, and has given final approval of the version to be published. B.D. made substantial contributions to the formal analysis and interpretation of the data, writing and review of the manuscript, and has given final approval of the version to be published. B.V. made substantial contribution to the investigation, review and editing of the manuscript, and has given final approval of the version to be published. J.L. made substantial contribution to the methodology and investigation, reviewed and edited the manuscript, and has given final approval of the version to be published. J.N. made substantial contribution to the study methodology, provided supervision/oversight, reviewed and edited the manuscript, and has given final approval of the version to be published. D.W. made substantial contribution to conception and design of the study and its methodology, data curation and analysis, review and editing of the manuscript, and has given final approval of the version to be published. C.L. made substantial contribution to the conception, design and methodology of the study, provided supervision and oversight, reviewed and edited the manuscript, and has given final approval of the version to be published. E.D. made substantial contribution to the methodology of the study, reviewed and edited the manuscript, and has given final approval of the version to be published. D.G. made substantial contribution to the study methodology and data curation, provided supervision/oversight, participated in writing and editing of the manuscript, and has given final approval of the version to be published. S.S. provided substantial contribution to the study methodology, provided supervision/oversight, reviewed and edited the manuscript, and has given final approval of the version to be published. A.P. provided substantial contribution to the study investigation, participated in writing and editing of the manuscript, and has given final approval of the version to be published. R.H. provided substantial contribution to the conception and design of the study, supervision/oversight for the investigation, review and editing of the manuscript, and has given final approval of the version to be published.

\section{ADDITIONAL INFORMATION}

Competing interests: D.A.G. is founder and chief scientific and strategy advisor at Salimetrics LLC and Salivabio LLC. The nature of those relationships is managed by the policies of the committees on conflict of interest at the Johns Hopkins University School of Medicine and the University of California at Irvine. All the remaining authors declare no competing interests.

Publisher's note: Springer Nature remains neutral with regard to jurisdictional claims in published maps and institutional affiliations.

\section{APPENDIX}

\section{NRN Steering Committee Chairs}

Alan H. Jobe, MD PhD, University of Cincinnati (2003-2006).

Michael S. Caplan, MD, University of Chicago, Pritzker School of Medicine (2006-2011).

Richard A. Polin, MD, Division of Neonatology, College of Physicians and Surgeons, Columbia University, (2011-present).

Abbot R. Laptook, MD; Angelita M. Hensman, MS RNC-NIC; Elisa Vieira, RN BSN; Emilee Little, RN BSN; Katharine Johnson, MD; Barbara Alksninis, PNP; Mary Lenore Keszler, MD; Andrea M. Knoll; Theresa M. Leach, MEd CAES; Elisabeth C. McGowan, MD; Victoria E. Watson, MS CAS-Alpert Medical School of Brown University and Women \& Infants Hospital of Rhode Island (U10 HD27904).

Michele C. Walsh, MD MS; Avroy A. Fanaroff, MD; Deanne E. Wilson-Costello, MD; Nancy S. Newman, RN; Bonnie S. Siner, RN; Arlene Zadell, RN; Julie DiFiore, BS; Monika Bhola, MD; Harriet G. Friedman, MA; Gulgun Yalcinkaya, MD-Case Western Reserve University, Rainbow Babies \& Children's Hospital (U10 HD21364, M01 RR80). Ronald N. Goldberg, MD; C. Michael Cotten, MD MHS; Kathryn E. Gustafson, PhD; Ricki F. Goldstein, MD; Patricia Ashley, MD; Kathy J. Auten, MSHS; Kimberley A. Fisher, PhD FNP-BC IBCLC; Katherine A. Foy, RN; Sharon F. Freedman, MD; Melody B. Lohmeyer, RN MSN; William F. Malcolm, MD; David K. Wallace, MD MPH—Duke University School of Medicine, University Hospital, and Duke Regional Hospital (U10 HD40492, M01 RR30).
David P. Carlton, MD; Barbara J. Stoll, MD; Ira Adams-Chapman, MD; Susie Buchter, MD; Anthony J. Piazza, MD; Sheena Carter, PhD; Sobha Fritz, PhD; Ellen C. Hale, RN BS CCRC; Amy K. Hutchinson, MD; Maureen Mulligan LaRossa, RN; Yvonne Loggins, RN, Diane Bottcher, RN-Emory University, Children's Healthcare of Atlanta, Grady Memorial Hospital, and Emory Crawford Long Hospital (U10 HD27851, RR25008, M01 RR39).

Stephanie Wilson Archer, MA-Eunice Kennedy Shriver National Institute of Child Health and Human Development.

Brenda B. Poindexter, MD MS; Gregory M. Sokol, MD; Heidi M. Harmon, MD MS; LuAnn Papile, MD; Abbey C. Hines, PsyD; Leslie D. Wilson, BSN CCRC; Dianne E. Herron, RN; Lucy Smiley, CCRC - Indiana University, University Hospital, Methodist Hospital, Riley Hospital for Children, and Wishard Health Services (U10 HD27856, M01 RR750). Kathleen A. Kennedy, MD MPH; Jon E. Tyson, MD MPH; Andrea F. Duncan, MD MSClinRes; Allison G. Dempsey, PhD; Janice John, CPNP; Patrick M. Jones, MD MA; M. Layne Lillie, RN BSN; Saba Siddiki, MD; Daniel K. Sperry, RN-McGovern Medical School at The University of Texas Health Science Center at Houston and Children's Memorial Hermann Hospital (U10 HD21373).

Carol J. Blaisdell, MD, Victoria Pemberton RNC, MS, CCRC-National Heart, Lung, and Blood Institute.

Abhik Das, PhD; Dennis Wallace, PhD; Marie G. Gantz, PhD; Jeanette O'Donnell Auman, BS; Jane A. Hammond, PhD; W. Kenneth Poole, PhD (deceased)-RTI International (U10 HD36790).

Krisa P. Van Meurs, MD; David K. Stevenson, MD; M. Bethany Ball, BS CCRC; Maria Elena DeAnda, PhD; Gabrielle T. Goodlin, BAS-Stanford University and Lucile Packard Children's Hospital (U10 HD27880, UL1 RR25744, M01 RR70).

Ivan D. Frantz III, MD; John M. Fiascone, MD; Elisabeth C. McGowan, MD; Anne Kurfiss, MPH; Brenda L. MacKinnon, RNC; Ellen Nylen, RN BSN; Ana Brussa, MS OTR/L; Cecelia Sibley, PT MHA-Tufts Medical Center, Floating Hospital for Children (U10 HD53119, M01 RR54).

Waldemar A. Carlo, MD; Namasivayam Ambalavanan, MD; Monica V. Collins, RN BSN MaEd; Shirley S. Cosby, RN BSN; Vivien A. Phillips, RN BSN; Kristy Domanovich, PhD; Sally Whitley, MA OTR-L FAOTA; Leigh Ann Smith, CRNP; Carin R. Kiser, MDUniversity of Alabama at Birmingham Health System and Children's Hospital of Alabama (U10 HD34216, M01 RR32).

Neil N. Finer, MD; Donna Garey, MD; Maynard R. Rasmussen; MD; Paul R. Wozniak, MD; Yvonne E. Vaucher, MD MPH; Martha G. Fuller, PhD RN; Natacha Akshoomoff, PhD; Wade Rich, BSHS RRT; Kathy Arnell, RNC; Renee Bridge, RN-University of California San Diego Medical Center and Sharp Mary Birch Hospital for Women (U10 HD40461). Edward F. Bell, MD; Tarah T. Colaizy, MD MPH; John A. Widness, MD; Jonathan M. Klein, MD; Karen J. Johnson, RN BSN; Michael J. Acarregui, MD; Diane L. Eastman, RN CPNP MA; Tammy L. V. Wilgenbusch, PhD—University of lowa (U10 HD53109, UL1 TR442, M01 RR59).

Robin K. Ohls, MD; Janell Fuller, MD; Conra Backstrom Lacy, RN; Rebecca A. Thomson, RN BSN; Sandra Brown, RN BSN-University of New Mexico Health Sciences Center (R01 HL117764, U10 HD53089, M01 RR997).

Pablo J. Sánchez, MD; Roy J. Heyne, MD; Charles R. Rosenfeld, MD; Walid A. Salhab, MD; Luc Brion, MD; Sally S. Adams, MS RN CPNP; James Allen, RRT; Laura Grau, RN; Alicia Guzman; Gaynelle Hensley, RN; Elizabeth T. Heyne, PsyD PA-C; Jackie F. Hickman, RN; Lizette E. Lee, RN; Melissa H. Leps, RN; Linda A. Madden, RN CPNP; Melissa Swensen Martin, RN; Nancy A. Miller, RN; Janet S. Morgan, RN; Araceli Solis, RRT; Catherine Twell Boatman, MS CIMI; Diana M Vasil, MSN BSN RNC-NIC—University of Texas Southwestern Medical Center at Dallas, Parkland Health \& Hospital System, and Children's Medical Center Dallas (U10 HD40689, M01 RR633).

Bradley A. Yoder, MD; Roger G. Faix, MD; Shawna Baker, RN; Karen A. Osborne, RN BSN CCRC; Carrie A. Rau, RN BSN CCRC; Sarah Winter, MD; Sean D. Cunningham, PhD; Ariel C. Ford, PsyD-University of Utah Medical Center, Intermountain Medical Center, LDS Hospital, and Primary Children's Medical Center (U10 HD53124, M01 RR64).

Athina Pappas, MD; Beena G. Sood, MD MS; Rebecca Bara, RN BSN; Thomas L. Slovis, MD (deceased); Laura A. Goldston, MA; Mary Johnson, RN BSN-Wayne State University, Hutzel Women's Hospital, and Children's Hospital of Michigan (U10 HD21385).

\section{REFERENCES}

1. Barker, D. J. et al. Fetal nutrition and cardiovascular disease in adult life. Lancet 341, 938-941 (1993). Review.

2. Reynolds, R. M. Glucocorticoid excess and the developmental origins of disease: two decades of testing the hypothesis--2012 Curt Richter Award Winner. Psychoneuroendocrinology 38, 1-11 (2013). 2013.

3. Cottrell, E. C., Holmes, M. C., Livingstone, D. E., Kenyon, C. J. \& Seckl, J. R. Reconciling the nutritional and glucocorticoid hypotheses of fetal programming. FASEB. J. 26, 1866-1874 (2012).

4. Economides, D. L., Nicolaides, K. H., Linton, E. A., Perry, L. A. \& Chard, T. Plasma cortisol and adrenocorticotropin in appropriate and small for gestational age fetuses. Fetal Ther. 3, 158-164 (1988). 
5. McTernan, C. L. et al. Reduced placental 11 beta-hydroxysteroid dehydrogenase type 2 mRNA levels in human pregnancies complicated by intrauterine growth restriction: an analysis of possible mechanisms. J. Clin. Endocrinol. Metab. 86, 4979-4983 (2001).

6. Ibáñez, L., Potau, N., Marcos, M. V. \& de Zegher, F. Exaggerated adrenarche and hyperinsulinism in adolescent girls born small for gestational age. J. Clin. Endocrinol. Metab. 84, 4739-4741 (1999).

7. Francois, I. \& de Zegher, F. Adrenarche and fetal growth. Pediatr. Res. 41, 440-442 (1997).

8. Ong, K. K. et al. Avon Longitudinal Study of Parents and Children Study Team. Opposing influences of prenatal and postnatal weight gain on adrenarche in normal boys and girls. J. Clin. Endocrinol. Metab. 89, 2647-2651 (2004).

9. de Jong, F., Monuteaux, M. C., van Elburg, R. M., Gillman, M. W. \& Belfort, M. B. Systematic review and meta-analysis of preterm birth and later systolic blood pressure. Hypertension 59, 226-234 (2012).

10. Kaseva, N. et al. Blunted hypothalamic-pituitary-adrenal axis and insulin response to psychosocial stress in young adults born preterm at very low birth weight. Clin. Endocrinol. 80, 101-106 (2014).

11. Meuwese, C. L. et al. Growth-restricted preterm newborns are predisposed to functional adrenal hyperandrogenism in adult life. Eur. J. Endocrinol. 163, 681-689 (2010).

12. Wells, N. et al. Anthropometric trends from 1997 to 2012 in infants born at $\leqslant 28$ weeks' gestation or less. J. Perinatol. 37, 521-526 (2017).

13. Donaldson, A., Nicolini, U., Symes, E. K., Rodeck, C. H. \& Tannirandorn, Y. Changes in concentrations of cortisol, dehydroepiandrosterone sulphate and progesterone in fetal and maternal serum during pregnancy. Clin. Endocrinol. 35, 447-451 (1991).

14. Watterberg, K. L. et al. Prophylaxis of early adrenal insufficiency to prevent bronchopulmonary dysplasia: a multicenter trial. Pediatrics 114, 1649-1657 (2004).

15. Watterberg, K. L. et al. Effect of dose on response to ACTH in extremely low birth weight infants. J. Clin. Endocrinol. Metab. 90, 6380-6385 (2005).

16. Finer, N. N. et al. Early CPAP versus surfactant in extremely preterm infants. New Engl. J. Med. 362, 1970-1979 (2010).

17. Hintz, S. R. et al. Preterm neuroimaging and school-age cognitive outcomes. Pediatrics 42, e20174058 (2018).

18. National High Blood Pressure Education Program Working Group on High Blood Pressure in Children and Adolescents. The fourth report on the diagnosis, evaluation and treatment of high blood pressure in children and adolescents. Pediatrics 114, 555-576 (2004).

19. Granger, D. A., Schwartz, E. B., Booth, A., Curran, M. \& Zakaria, D. Assessing dehydroepiandrosterone in saliva: a simple radioimmunoassay for use in studies of children, adolescents and adults. Psychoneuroendocrinology 24, 567-579 (1999).

20. Ahn, R. S., Lee, Y. J., Choi, J. Y., Kwon, H. B. \& Chun, S. I. Salivary cortisol and DHEA levels in the Korean population: age-related differences, diurnal rhythm, and correlations with serum levels. Yonsei. Med. J. 48, 379-388 (2007).

21. Granger, D. A. et al. Focus on methodology: salivary bioscience and research on adolescence: an integrated perspective. J. Adolesc. 35, 1081-1095 (2012).

22. Fenton, T. R. \& Kim, J. H. A systematic review and meta-analysis to revise the Fenton growth chart for preterm infants. BMC Pediatr. 13:59 (2013).
23. Moulton, L. H. \& Halsey, N. A. A mixture model with detection limits for regression analyses of antibody response to vaccine. Biometrics 51, 1570-1578 (1995).

24. Voutilainen, R. \& Jääskeläinen, J. Premature adrenarche: etiology, clinical findings, and consequences. J. Steroid Biochem. Mol. Biol. 145, 226-236 (2015).

25. Girgis, R. et al. Ethnic differences in androgens, IGF-I and body fat in healthy prepubertal girls. Pediatr. Endocrinol. Metab. 13, 497-503 (2000).

26. Finken, M. J. et al. Glucocorticoid programming in very preterm birth. Horm. Res. Paediatr. 85, 221-231 (2016).

27. Tenhola, S. et al. Increased adrenocortical and adrenomedullary hormonal activity in 12-year-old children born small for gestational age. J. Pediatr. 141, 477-482 (2002).

28. Victoria, N. C. \& Murphy, A. Z. The long-term impact of early life pain on adult responses to anxiety and stress: Historical perspectives and empirical evidence. Exp. Neurol. 275(Pt 2), 261-273 (2016).

29. Maurer, N. et al. Salivary and hair glucocorticoids and sleep in very preterm children during school age. Psychoneuroendocrinology 72, 166-174 (2016).

30. Brummelte, S. et al. Cortisol levels in former preterm children at school age are predicted by neonatal procedural pain-related stress. Psychoneuroendocrinology 51, 151-163 (2015).

31. Grunau, R. E. Neonatal pain in very preterm infants: long-term effects on brain, neurodevelopment and pain reactivity. Rambam Maimonides Med. J. 4, e0025 (2013).

32. Kalmakis, K. A., Meyer, J. S., Chiodo, L. \& Leung, K. Adverse childhood experiences and chronic hypothalamic-pituitary-adrenal activity. Stress 18, 446-450 (2015).

33. Leneman, K. B., Donzella, B., Desjardins, C. D., Miller, B. S. \& Gunnar, M. R. The slope of cortisol from awakening to $30 \mathrm{~min}$ post-wake in postinstitutionalized children and early adolescents. Psychoneuroendocrinology 96, 93-99 (2018).

34. Steudte-Schmiedgen, S., Kirschbaum, C., Alexander, N. \& Stalder, T. An integrative model linking traumatization, cortisol dysregulation and posttraumatic stress disorder: Insight from recent hair cortisol findings. Neurosci. Biobehav. Rev. 69 124-135 (2016).

35. Kerkhof, G. F., Willemsen, R. H., Leunissen, R. W., Breukhoven, P. E. \& HokkenKoelega, A. C. Health profile of young adults born preterm: negative effects of rapid weight gain in early life. J. Clin. Endocrinol. Metab. 97, 4498-4506 (2012).

36. Huysman, M. W., Hokken-Koelega, A. C., De Ridder, M. A. \& Sauer, P. J. Adrenal function in sick very preterm infants. Pediatr. Res. 48, 629-633 (2000).

37. $\mathrm{Ng}, \mathrm{P}$. C. et al. Reference ranges and factors affecting the human corticotropinreleasing hormone test in preterm, very low birth weight infants. J. Clin. Endocrinol. Metab. 87, 4621-4628 (2002).

38. Xi, B. et al. Can pediatric hypertension criteria be simplified? A prediction analysis of subclinical cardiovascular outcomes from the Bogalusa Heart Study. Hypertension 69, 6sz91-696sz91 (2017).

39. Corvalán, C., Uauy, R. \& Mericq, V. Obesity is positively associated with dehydroepiandrosterone sulfate concentrations at $7 \mathrm{y}$ in Chilean children of normal birth weight. Am. J. Clin. Nutr. 97, 318-325 (2013).

40. Stoltz Sjöström, E. et al. Nutrient intakes independently affect growth in extremely preterm infants: results from a population-based study. Acta Paediatr. 102, 1067-1074 (2013).

41. Sanders, M. R. \& Hall, S. L. Trauma-informed care in the newborn intensive care unit: promoting safety, security and connectedness. J. Perinatol. 38, 3-10 (2018). 